ORIGINAL ARTICLE

\title{
Effects of 6-weeks Bhastrika Pranayama Intervention on health- related components of physical fitness
}

\author{
Baljinder S. Bal ${ }^{1 \mathrm{ABCDE}}$, Parmjit Kaur ${ }^{2 \mathrm{ABCD}}$, Davinder Singh ${ }^{3 \mathrm{ABCD}}$, Manoj Bhardwaj ${ }^{\mathrm{ABCD}}$ \\ ${ }^{1}$ Department of Physical Education (T), Guru Nanak Dev University, Amritsar, Punjab, India \\ ${ }^{2}$ Department of Physical Education, PCM S.D. College for Women, Jalandhar, Punjab, India \\ ${ }^{3}$ Department of Physical Education, Kanya Maha Vidyalaya (Autonomous), Jalandhar Punjab, India \\ ${ }^{4}$ Department of Physical Education (T), Guru Nanak Dev University, Amritsar, Punjab, India
}

Authors' Contribution: A - Study design; B - Data collection; C - Statistical analysis; D - Manuscript Preparation; E - Funds Collection.

\begin{abstract}
Background The present study investigated the effects of 6-weeks bhastrika pranayama intervention (BPI) program on and Study Aim health-related components of physical fitness.

Material and We used a quasi-experimental design with fifty-two healthy girls (Mean \pm SD; age, 23.6346 $\pm 1.1551 \mathrm{yrs}$; Methods body height, $158.0961 \pm 3.8616 \mathrm{~cm}$; body weight, $55.6826 \pm 3.4002 \mathrm{~kg}$ ) from Guru Nanak Dev University, Amritsar, Punjab, India. The subjects were divided into two groups: Group-A: Bhastrika Pranayama Intervention (BPI); $\left(n_{1}=26\right)$ and Group-B: Control; $\left(n_{2}=26\right)$. The sample size $(\mathrm{N}=52)$ was calculated using the $G^{*}$ Power 3.1.9.7 software. A power of 0.80 (1- $\beta$ err prob) and significance level (a) of 0.05 . Subjects from both groups (pranayama and control) were assessed at baseline and right after 6-weeks. Group-A: $\left(n_{1}=26\right)$ subjected to BPI and Group-B: $\left(\mathrm{n}_{2}=26\right)$ with no training.

Results: $\quad$ As compared BPI with the control group, the BPI group had a positive effect on selected health-related components of physical fitness (maximal oxygen consumption - VO2 max 1.3\%; flexibility 1.8\%; muscle strength 0.2.\%). The 6-weeks Bhastrika Pranayama intervention program had no effect on the BPI group with respect to the parameter muscular endurance.

Conclusions: Daily practice of Bhastrika pranayama helps to keep lungs more efficient. Additional research is required to completely comprehend the consequences of this breathing exercise. Bhastrika pranayama is known for oxygen-based breathing exercise which helps to fill up the lungs with more oxygen. Bhastrika pranayama interventions with short as well as long duration in future research studies could be beneficial for healthy individuals with respect to health-related fitness components.

Keywords: $\quad$ bhastrika pranayama, maximal oxygen, flexibility, muscular strength, muscular endurance.
\end{abstract}

\section{Introduction}

Yoga is a traditional Indian culture practice that is regarded to be the science of holistic life. Disciplined living (Yama and Niyama), cleaning procedures (Kriya), bodily postures (Asana), breath management (Pranayama), concentration (Dharana), and meditation are all part of the Yoga tradition (Dhyana) $[1,2]$. In recent years, there has been a surge in interest in learning more about the advantages of the various Yoga practices. [3, 4]. There have been scientific researches on the effects of individual Yoga practises or their combinations on both healthy people and persons with various diseases. [5]. Yoga practice can be performed by people of any age group and gender and can be applied to children during their developmental phase of life [6].

A recent study suggested that yoga practice in school children may be an effective way to improve their health $[7,8]$. It has been observed that yogic exercise practice in school setups may be useful to develop flexibility, mood and self-regulation skills related to emotion and stress among children [9]. Maharishi Patanjali, in his Ashtanga yoga, has given more importance to pranayama than

\footnotetext{
(c) Baljinder S. Bal, Parmjit Kaur, Davinder Singh, Manoj Bhardwaj, 2021

doi:10.15561/20755279.2021.0404
}

asana for good health [10]. Purak (inhalation), Kumbhak (retention), and Rechak (exhalation) are the three phases of Pranayama. [11]. Thus, Pranayama means "breathing techniques" or "breathe control". The important aspects of breathing utilized in pranayama include: Puraka Inhalation, Rechaka - Exhalation, Kumbhaka - Retention, which is further divided into Antar Kumbhaka - Inhalation Retention (after Inhaling) and Bahir Kumbhaka Exhalation Retention (after exhaling). According to Maharshi Patanjali's Yoga Sutras state (2:49) "Pranayama is the pause in the movement of inhalation and exhalation when that is secured" (Fig. 1) [12].

Therefore, the significant parts of pranayama are essentially kumbhaka or breathe retention. In order to achieve kumbhaka effectively, the function of respiration must be gradually controlled. As a result, inhalation and exhalation are given more emphasis in the beginning of pranayama practises in order to strengthen the lungs and balance the neurological and pranic systems in preparation for the practice of kumbhaka. Prana is a subtle aspect of the body. It has a visible aspect which is the air we breathe and an invisible aspect, which is the energy that flows in the body through various channels and sustains it. Prana also connects the gross body (annamaya kosa) with the 
mental body (manomaya kosa). Hence the Upanishads describe it often as the soul of the gross body and equate it with Atman or the essence of Brahman. According to Kathopanishad (2:3:2): "This whole world- whatever there is- vibrates having originated from prana" [12]. Hence, prana controls all physical tasks including the breath, supply of oxygen, digestion and elimination. The function of the human body is much like a transformer, receiving energy from the universal flow of prana, distributing that energy, and then eliminating it. Figure 2.

In human beings, the breath is an active connection between the body and mind while the Pranayama is considered as manipulation of one own breathing [13]. Different types of pranayama produce specific physiological responses and it greatly depends on the type and duration of the practice $[14,15,16]$. Nadisuddhi, Savitri, Kapalbhati, Bhastrika, Bhramari Pranayama, and so on are well known among them. Many physiological variables are influenced by pranayama practice. Evidence suggests that it has a beneficial effect on the cardiorespiratory system. $[17,18]$ on the other side with slow breathing resulting in a lower heart rate and lower systolic and diastolic blood pressure. [19], while fast breathing leads to a less robust, but consistent increase in heart rate [20, 21]. In fact, a prior study found that practising Bhastrika pranayama with a low respiratory rate (RR) reduced both systolic and diastolic blood pressure while also lowering heart rate slightly. [22]. In addition, variations in heart rate variability (HRV) support the indication that pranayama improves respiratory function and cardiac sympathovagal balance, both of which are vital psycho-physiological stress-related factors. [23, 24].

Physical exercise at work has decreased significantly in emerging countries like India as the work environment has become increasingly computerised among young adults. In addition, sedentary lifestyles and eating habits have been linked to a variety of health problems. Pranayama is one of the most often practiced supplemental or alternative interventions to obtain the greatest possible physical and mental health, according to recorded studies and data. To reduce the burden of non-communicable diseases and to improve the status of health and wellness in young female adults we designed the study to observe the effects of 6-weeks bhastrika pranayama intervention (BPI) program on health-related components of physical fitness.

\section{Material and Methods}

Participants.

We used a quasi-experimental design with fiftytwo healthy girls (Mean \pm SD; age, 23.6346 $\pm 1.1551 \mathrm{yrs}$; body height, $158.0961 \pm 3.8616 \mathrm{~cm}$; body weight, $55.6826 \pm 3.4002 \mathrm{~kg}$ ) from Guru Nanak Dev University, Amritsar, Punjab, India. The subjects were divided into two groups: Group-A: Bhastrika Pranayama Intervention (BPI); $\left(\mathrm{n}_{1}=26\right)$, and Group-B: Control; $\left(\mathrm{n}_{2}=26\right)$. The sample size $(\mathrm{N}=52)$ was calculated using the $\mathrm{G}^{*}$ Power 3.1.9.7 software. A power of 0.80 (1- $\beta$ err prob) and significance level $(\alpha)$ of 0.05 . Subjects from both groups (pranayama and control) were assessed at baseline and right after 6-weeks. Group-A: $\left(n_{1}=26\right)$ subjected to BPI program and Group-B: $\left(\mathrm{n}_{2}=26\right)$ with no training.

\section{Research Design}

Procedure:

Cooper's 12-minute run test was used to measure maximal oxygen consumption $\left(\mathrm{VO}_{2}\right.$ max), sit, and reach test was used to measure flexibility, handgrip strength test was used to measure muscular strength, while 1-minute sit-up test was used to measure muscular endurance. Subjects from both groups (pranayama and control) were assessed at baseline and right after 6-weeks.

Bhastrika Pranayama Intervention (BPI) Program:

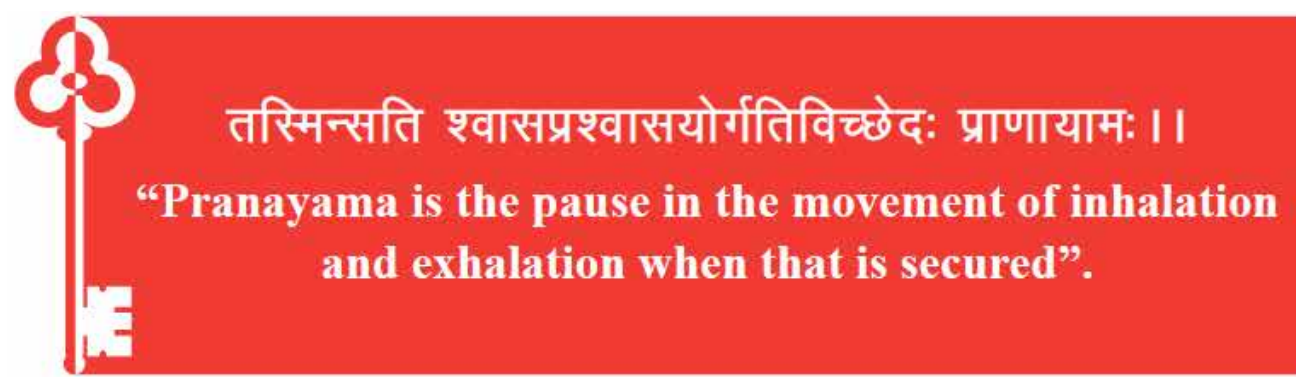

Figure 1. The actual pranayama is kumbhaka, the period of breath retention.

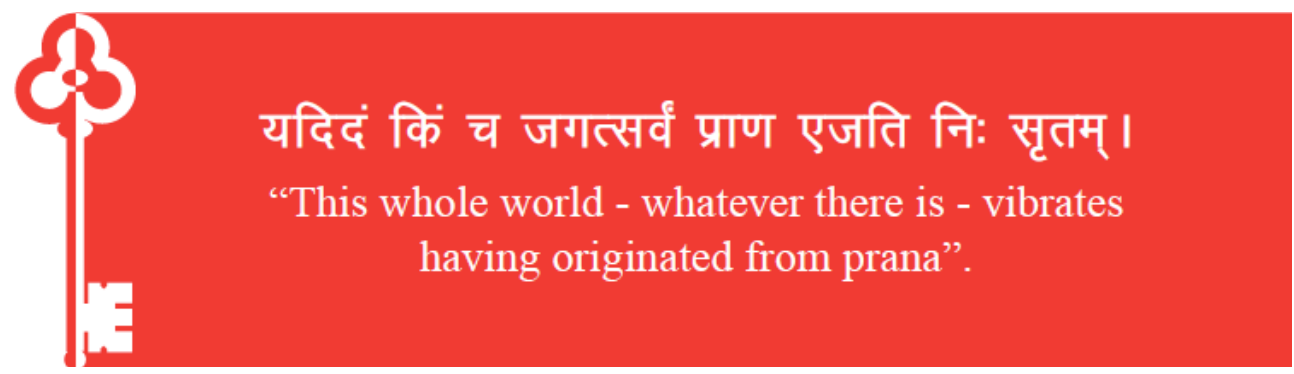

Figure 2. All this universe evolved (from prana) moves while Prana is a mighty terror, the thunderbolt uplifted; those who know this become immortal. 
Participants of the Bhastrika Pranayama Intervention (BPI) group were asked to sit in a comfortable meditative posture, with their hands resting on the knees in chin mudra. Then asked to keep the head and spine straight, close the eyes and relax the whole body. They were asked to take a deep breath in through both the nostrils while making sure that their mouth does not open at all while doing this pranayama. After this, they were asked to release the filled breath through both the nostrils rapidly. They continued in this manner, counting ten breaths. They took a deep breath in and breathe out rapidly. This is one round. Participants practiced up to five rounds.

Statistical Analysis.

This study's data analysis procedure was divided into four sections: - The G*Power 3.1.9.7 software was used in the first section. The normality of data was checked by using the Shapiro-Wilk test of normality in the second section. A descriptive analysis was used in the third section to describe the data distribution. The hypothesis testing with analysis of covariance (ANCOVA) test was included in the fourth section. The level of significance was set at 0.05 . The statistical techniques were used to analyze the data on Statistical Package for Social Science (SPSS) version 26.0.

The Protocol of power analysis and demographics of subjects (age, body height and body weight) is brought forth in Figure 3 \& Figure 4 respectively.

Protocol of power analysis was done to get the required number of sample $(\mathrm{n}=52)$ for the experimental study with large effect size (0.40), as to obtain the strong impact on power $(1-\beta$ err prob $=0.80)$ of the study at $\alpha$ err prob $=0.05$ (fig.3).

Demographics of subjects showing Mean $\pm \mathrm{SD}$; age, $23.6346 \pm 1.1551 \mathrm{yrs}$; body height, $158.0961 \pm 3.8616 \mathrm{~cm}$; body weight, $55.6826 \pm 3.4002 \mathrm{~kg}$ (fig.4).

Table 1 shows that the pre-test \& post-test data of health-related components of physical fitness including maximal oxygen consumption $\left(\mathrm{VO}_{2} \max \right)$ : $\mathrm{BPI}(\mathrm{p}=$ $.128 \& .354)$ and Control $(\mathrm{p}=.280 \& .541)$, flexibility: BPI $(\mathrm{p}=.178 \& .094)$ and Control $(\mathrm{p}=.123 \& .163)$, muscular strength: BPI $(\mathrm{p}=.270 \& .241)$ and Control $(p=.544 \& .188)$, muscular endurance: BPI $(p=.275$ $\&$.113) and Control $(p=.653 \& .295)$ of subjects were normally distributed as evident from Shapiro-Wilk test for normality. As a result, the p-values of the bhastrika pranayama intervention (BPI) and control groups' pre-test and post-test data were statistically insignificant ( $\mathrm{p}>.05)$, indicating that the data were normally distributed.

The summary of the descriptive statistics regarding the health-related components of physical fitness of pretest \& post-test of BPI group and pre-test $\&$ post-test of a control group for subjects is brought forth in Table 2 and Table 3 respectively.

\section{Results}

Maximal Oxygen Consumption $\left(V_{2}\right.$, max):

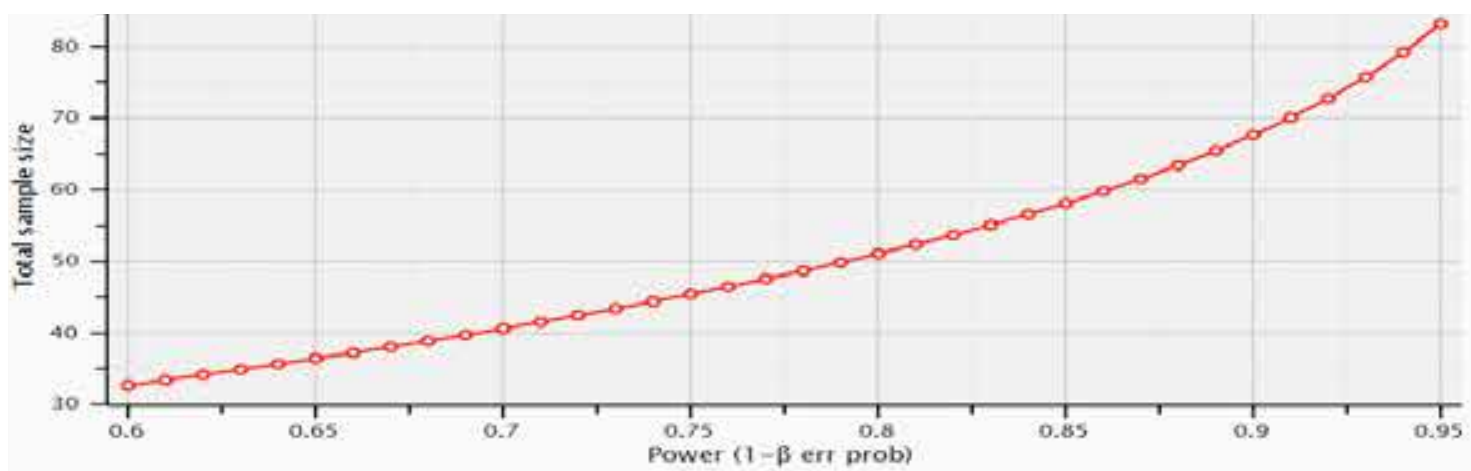

Figure 3. Protocol of power analysis

Table 1. Normal distribution of data by utilizing Shapiro-Wilk Test of Normality of bhastrika pranayama intervention (BPI) group and control group of health-related components of physical fitness.

\begin{tabular}{|c|c|c|c|c|}
\hline \multicolumn{5}{|c|}{ Shapiro-Wilk Test of Normality } \\
\hline \multicolumn{5}{|c|}{ Maximal Oxygen Consumption ( $\left.\mathrm{VO}_{2} \max \right)(\mathrm{ml} / \mathrm{kg} / \mathrm{min})$} \\
\hline & Bhastrika Pranayama & Bhastrika Pranayama & Control Group & Control Group \\
\hline & $\begin{array}{l}\text { Intervention (BPI) Group Pre- } \\
\text { Test }\end{array}$ & $\begin{array}{l}\text { Intervention (BPI) Group } \\
\text { Post-Test }\end{array}$ & Pre-Test & Post-Test \\
\hline Sig. & .128 & .354 & .280 & .541 \\
\hline \multicolumn{5}{|c|}{ Flexibility $(\mathrm{cm})$} \\
\hline Sig. & .178 & .094 & .123 & .163 \\
\hline \multicolumn{5}{|c|}{ Muscular Strength (kg) } \\
\hline Sig. & .270 & .241 & .544 & .188 \\
\hline \multicolumn{5}{|c|}{ Muscular Endurance (min) } \\
\hline Sig. & .275 & .113 & .653 & .295 \\
\hline
\end{tabular}




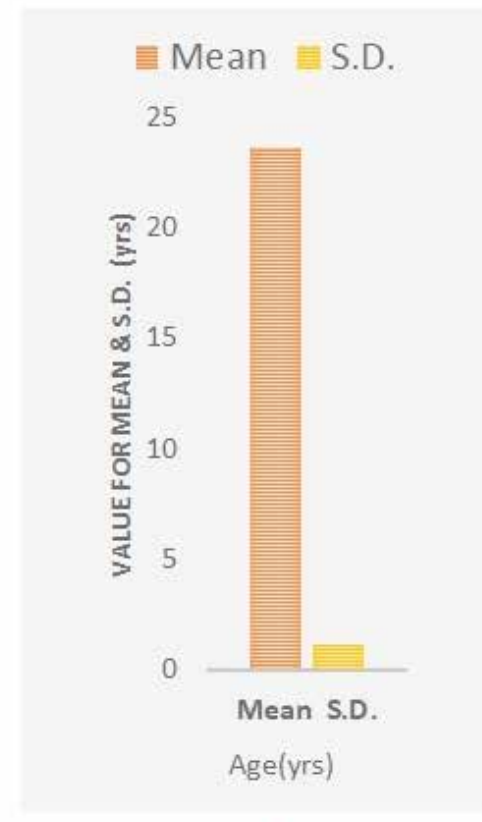

a.

Figure 4. Demographics of subjects showing

It is evident from the results that insignificant differences were noted between BPI and Control groups of girls on Maximal Oxygen Consumption $\left(\mathrm{VO}_{2}\right.$ max) since the $\mathrm{p}$-value .431 was greater than $(\mathrm{p}>0.05)$. In addition, the Partial Eta Squared value showed that 6-weeks of bhastrika pranayama intervention had a positive effect of $1.3 \%$ on the BPI group regarding the parameter Maximal Oxygen Consumption $\left(\mathrm{VO}_{2} \max \right)$.

Flexibility:

It is evident from the results that insignificant differences were noted between BPI and Control groups of girls on Flexibility since the p-value .351 was greater than $(\mathrm{p}>0.05)$. In addition, the Partial Eta Squared value showed that 6-weeks of bhastrika pranayama intervention had a positive effect of $1.8 \%$ on the BPI group regarding the parameter Flexibility.

Muscular Strength:

It is evident from the results that insignificant differences were noted between BPI and Control groups of girls on Muscular Strength since the p-value .784 was greater than $(\mathrm{p}>0.05)$. In addition, the Partial Eta Squared value showed that 6 -weeks of bhastrika pranayama intervention had a positive effect of $0.2 \%$ on the BPI group regarding the parameter Muscular Strength.

Muscular Endurance:

It is evident from the results that insignificant differences were noted between BPI and Control groups of girls on Muscular Endurance since the p-value .917 was greater than $(\mathrm{p}>0.05)$. In addition, the Partial Eta Squared value showed that 6 -weeks of bhastrika pranayama intervention had no effect on the BPI group regarding the parameter Muscular Endurance. The statistical analysis of results regarding health-related components of physical fitness including maximal oxygen consumption (VO2 max), flexibility, muscular strength, and muscular endurance have presented in Table 4 \& percentage increase shown in Figure 5.

\section{Discussion}

Our results open an exciting new avenue of study focused on short-term effects of bhastrika pranayama intervention of six weeks on healthy girls with positive effect on health-related components of physical fitness including $\mathrm{Vo}_{2}$ max $=1.3 \%$, flexibility $1.8 \%$, muscle strength $0.2 . \%$. As our study results with the positive impact of bhastrika pranayama intervention (BPI) are supported by other studies i.e., the bhastrika pranayama practiced on daily basis benefits in the maintenance of healthy lungs and can be easily incorporated into an athletic training program. This pranayama helps to strengthen the lungs' immunity [25]. Bhastrika Pranayama (breathing techniques/exercises) can be said to be advantageous to respiratory parameters for better functioning. Even in normal healthy participants, the functions of respiratory parameters, notably, were improved who participated voluntarily in this study [26]. Bhastrika exercises the diaphragm, the primary respiratory muscle that renews the residual air in the lungs [27]. In healthy University students, Anuloma-Viloma and Bhastrika Pranayama appear to be useful in enhancing physical health indices [28]. In addition, another study results showed that both slow and fast pranayamas for 12-weeks improve handgrip dynamometry characteristics, with fast pranayama being more effective than slow pranayama [29]. According to the literature, consistent hatha yoga practice can lead to enhancements in health-related aspects and could benefit to improve status of health and wellness [30]. Moreover, the present study findings acknowledged the beneficial effects of bhastrika pranayama besides the limitation of short duration in relation to health and wellness. Bhastrika 


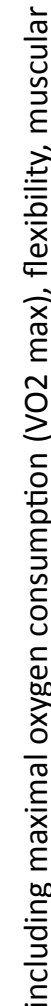

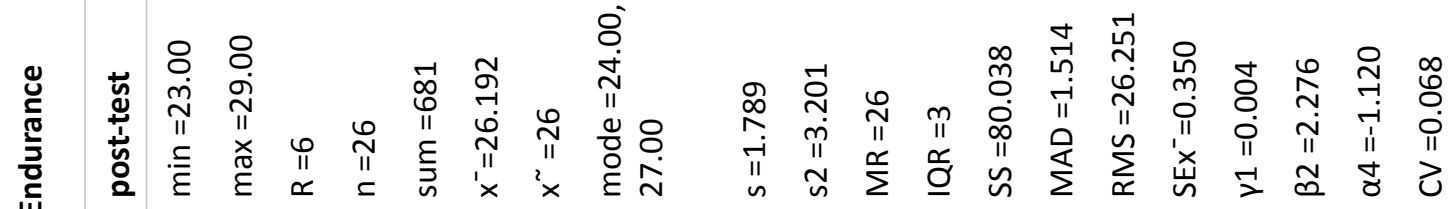

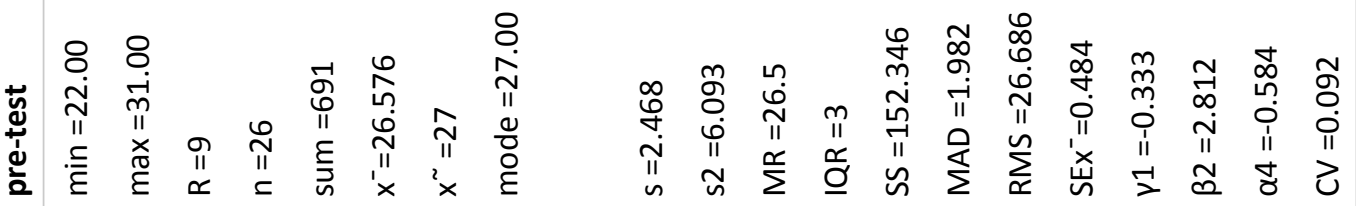

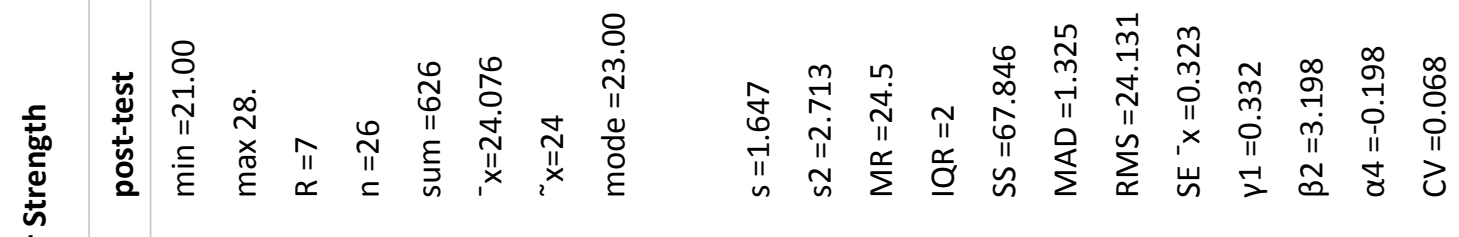

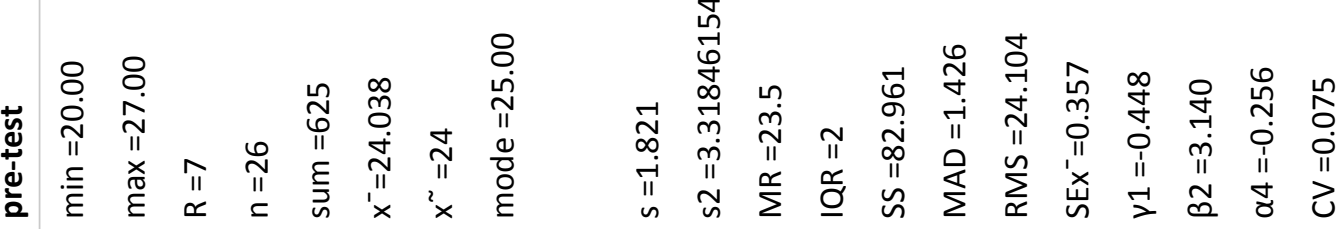

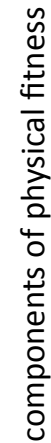

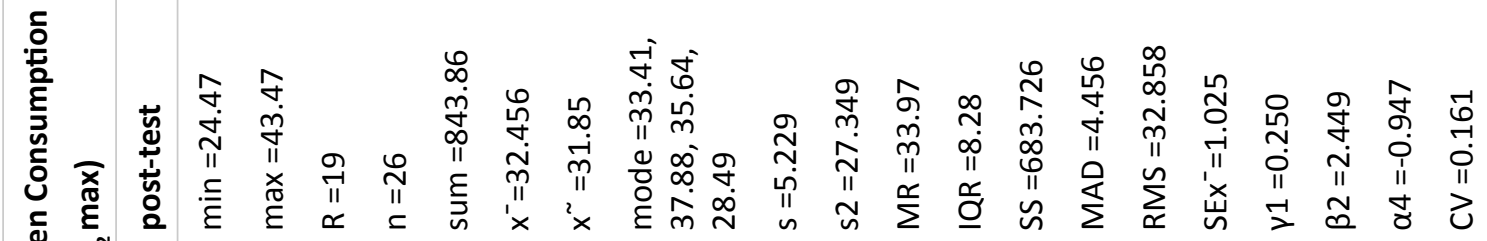

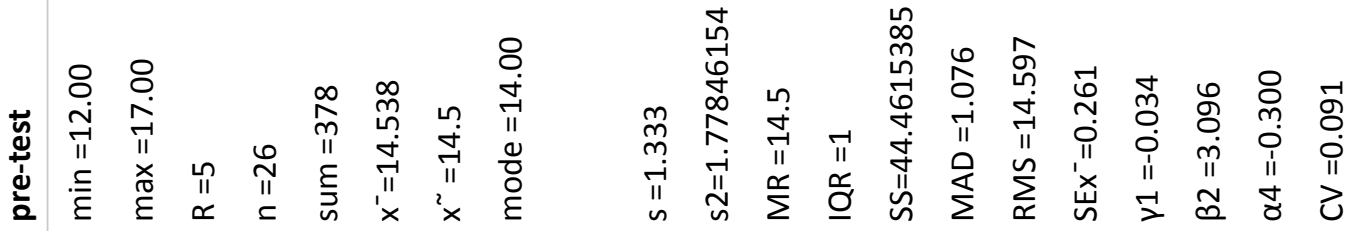

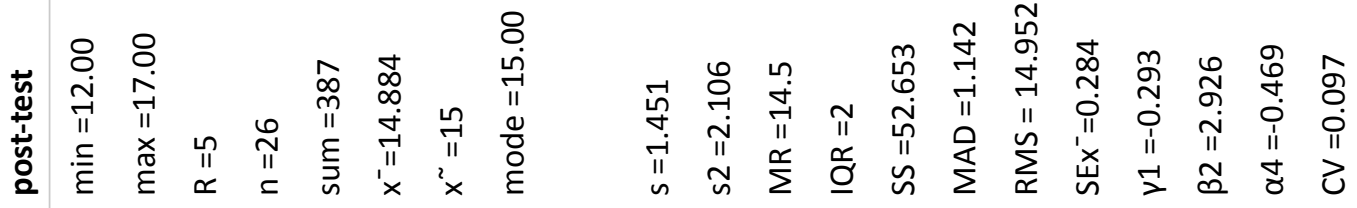

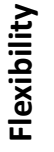

吾 范

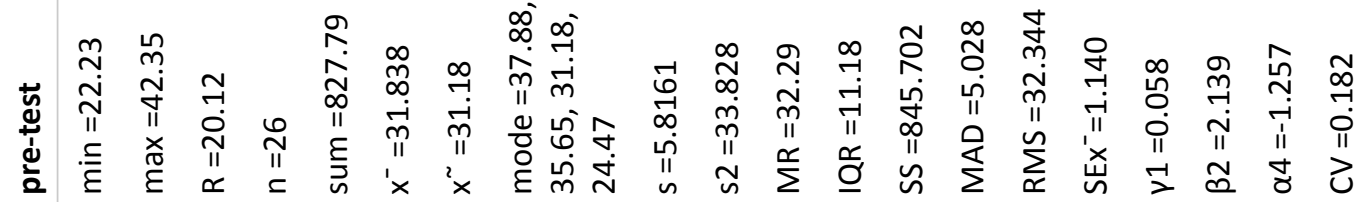




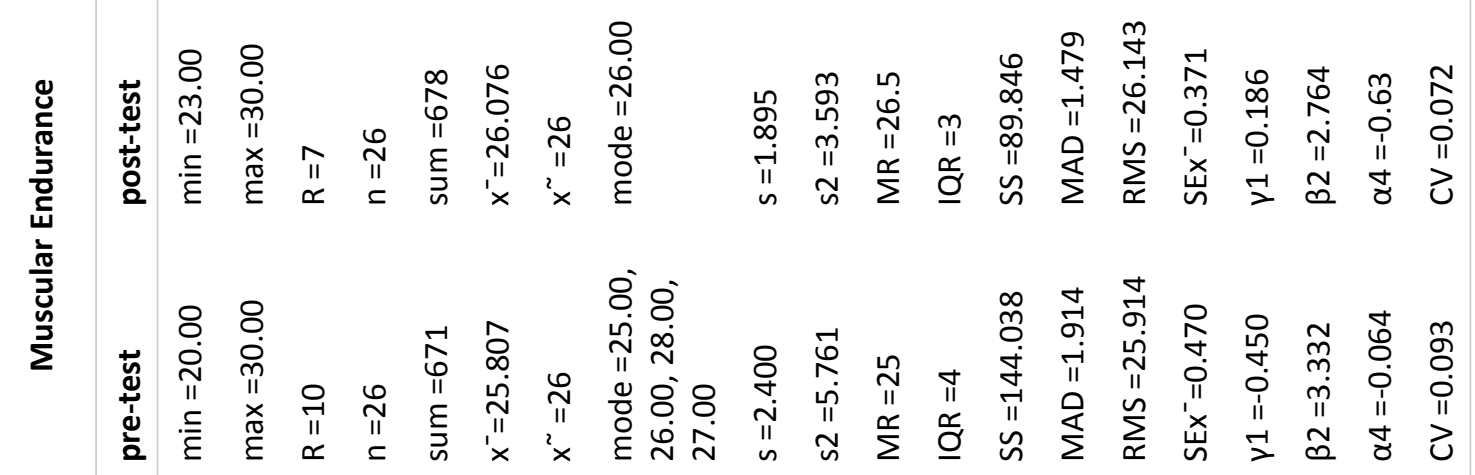

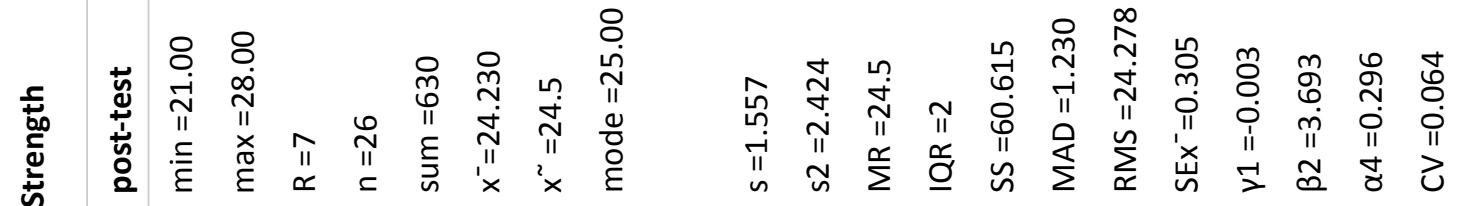

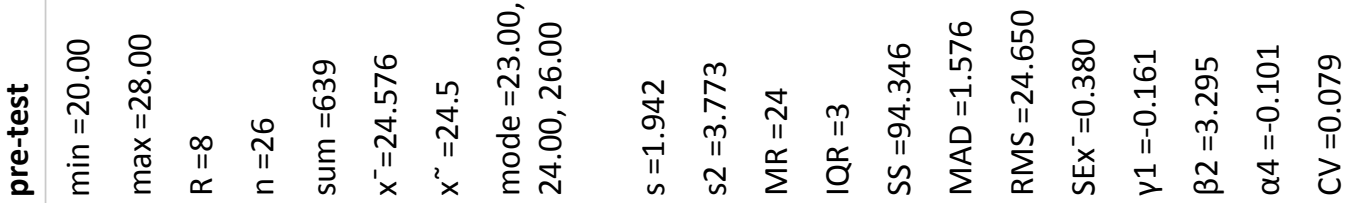

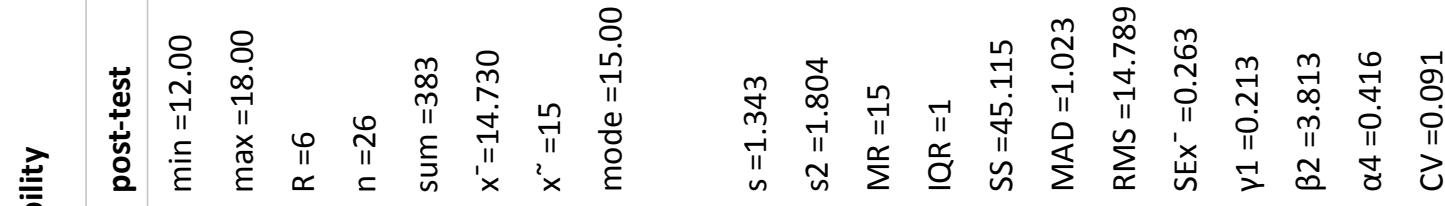

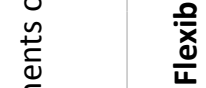


Table 4. Analysis of covariance (ANCOVA) results regarding the health-related components of physical fitness including maximal oxygen consumption (VO2 max), flexibility, muscular strength, and muscular endurance.

\begin{tabular}{|c|c|c|c|c|}
\hline \multicolumn{5}{|c|}{ Maximal Oxygen Consumption $\left(\mathrm{VO}_{2} \max \right)(\mathrm{ml} / \mathrm{kg} / \mathrm{min})$} \\
\hline Group & Mean士 S.D. & $\mathbf{F}$ & Sig. & Partial Eta Squared \\
\hline BPI Post-Test & $32.45 \pm 5.22$ & \multirow{2}{*}{.630} & \multirow{2}{*}{.431} & \multirow{2}{*}{.013} \\
\hline Control Post-Test & $31.49 \pm 4.19$ & & & \\
\hline \multicolumn{5}{|l|}{ Flexibility $(\mathrm{cm})$} \\
\hline BPI Post-Test & $14.88 \pm 1.45$ & \multirow{2}{*}{.885} & \multirow{2}{*}{.351} & \multirow{2}{*}{.018} \\
\hline Control Post-Test & $14.73 \pm 1.34$ & & & \\
\hline \multicolumn{5}{|c|}{ Muscular Strength (kg) } \\
\hline BPI Post-Test & $24.07 \pm 1.64$ & \multirow{2}{*}{.076} & \multirow{2}{*}{.784} & \multirow{2}{*}{.002} \\
\hline Control Post-Test & $24.23 \pm 1.55$ & & & \\
\hline \multicolumn{5}{|c|}{ Muscular Endurance (min) } \\
\hline BPI Post-Test & $26.19 \pm 1.78$ & \multirow{2}{*}{.011} & \multirow{2}{*}{.917} & \multirow{2}{*}{.000} \\
\hline Control Post-Test & $26.07 \pm 1.89$ & & & \\
\hline
\end{tabular}

NOTE: $p$ value $(p \geq .05)$ considered as insignificant.

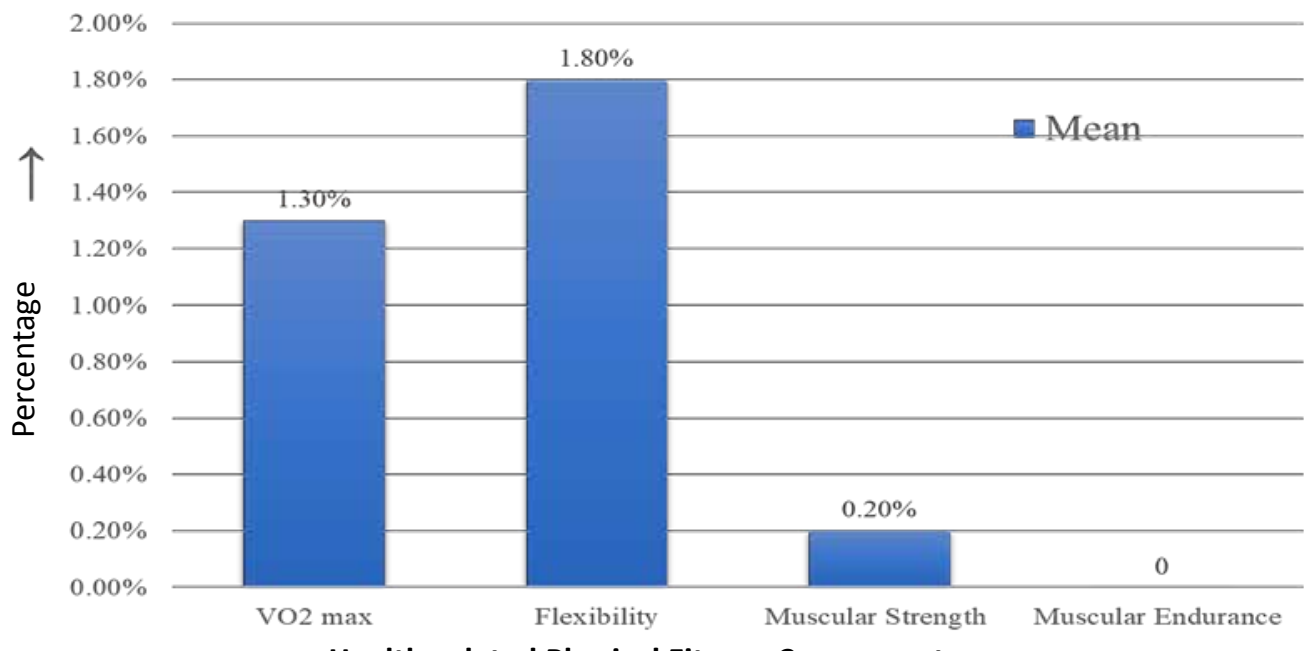

Health-related Physical Fitness Components

Figure 5. The increasing results in percentage \% of 6-Weeks bhastrika pranayama intervention (BPI) on each variable of health-related components of physical fitness for BPI group as compared to control group.

pranayama is known for oxygen-based breathing exercise which helps to fill up the lungs with more oxygen and exhale carbon dioxide $\left(\mathrm{CO}_{2}\right)$ from the body through nostrils. In the nutshell, Bhastrika pranayama interventions with short as well as long duration in future research studies could be beneficial for healthy individuals with respect to health-related fitness components.

\section{Conclusions}

According to the findings of our study, the daily practice of Bhastrika pranayama helps to keep lungs more efficient, but additional research is required to completely comprehend the consequences of this breathing exercise. Bhastrika pranayama can be easily incorporated into an athletic training program. However, it may be necessary to practice, experience for longer than six weeks to experience improvements. It's also likely that the effects of bhastrika pranayama are restricted by one's fitness or activity level; future research should investigate this more in-depth and evaluate a longer duration of pranayama practice.

\section{Consent}

Informed consent was obtained from all individual participants included in the study.

\section{Funding}

No external or internal funding was received for this work.

\section{Conflict of interests}

The authors declare no conflict of interest. 


\section{References}

1. Taimni IK. The science of yoga: the yoga-sutras of Patanjali in Sanskrit with Transliteration in Roman, Translation and Commentary in English. Theosophical Publishing House; 1999.

2. Muktibodhananda S. Hatha yoga Pradipika: light on hatha yoga. 2nd ed. Bihar: Yoga Publication Trust; 2002.

3. Jeter PE, Slutsky J, Singh N, Khalsa SBS. Yoga as a Therapeutic Intervention: A Bibliometric Analysis of Published Research Studies from 1967 to 2013. $J$ Altern Complement Med, 2015;21(10):586-92. https://doi.org/10.1089/acm.2015.0057

4. Sengupta P, Chaudhuri P, Bhattacharya K. Male reproductive health and yoga. Int $J$ Yoga, 2013;6(2):87-95. https://doi.org/10.4103/0973-6131.113391

5. Sengupta P. Health Impacts of Yoga and Pranayama: A Stateof-the-Art Review. Int J Prev Med, 2012; 3(7): 444-458.

6. Saoji AA, Raghavendra BR, Manjunath NK. Effects of yogic breath regulation: A narrative review of scientific evidence. J Ayurveda Integr Med, 2019;10(1):50-58. https://doi.org/10.1016/j.jaim.2017.07.008

7. Khalsa SB, Butzer B. Yoga in school settings: A research review. Ann $N$ Y Acad Sci, 2016;1373(1):45-55. https://doi.org/10.1111/nyas.13025

8. Frank J, Seifert G, Schroeder R, Gruhn B, Stritter W, Jeitler $\mathrm{M}$. Yoga in school sports improves functioning of autonomic nervous system in young adults: A non-randomized controlled pilot study. PLoS One, 2020;15(4): e0231299. https://doi.org/10.1371/journal.pone.0231299

9. Khalsa SB, Hickey-Schultz L, Cohen D, Steiner N, Cope $\mathrm{S}$. Evaluation of the mental health benefits of yoga in a secondary school: A preliminary randomized controlled trial. J Behav Health Serv Res, 2012;39(1):80-90. https://doi.org/10.1007/s11414-011-9249-8

10.Veerabhadrappa SG, Baljoshi VS, Khanapure S, Herur A, Patil S, Ankad RB, Chinagudi S. Effect of yogic bellows on cardiovascular autonomic reactivity. $J$ Cardiovasc Dis Res, 2011;2(4):223-7. https://doi.org/10.4103/0975-3583.89806

11.Saraswati SN. Prana, Pranayama, Prana Vidya. Yoga Publications Trust; 1994.

12.Nirajanananda SS. Prana and Pranayama. 2009.

13.Chodzinski J. The effect of rhythmic breathing on blood pressure in hypertensive adults. $J$ Undergrad Res, 2000;1 (6): 78-98.

14. Sharma VK, Trakroo M, Subramaniam V, Rajajeyakumar M, Bhavanani AB, Sahai A. Effect of fast and slow pranayama on perceived stress and cardiovascular parameters in young health-care students. Int J Yoga, 2013 ;6(2):104-10. https://doi.org/10.4103/0973-6131.113400

15.Turankar AV, Jain S, Patel SB, Sinha SR, Joshi AD, Vallish BN, Mane PR, Turankar SA. Effects of slow breathing exercise on cardiovascular functions, pulmonary functions \& galvanic skin resistance in healthy human volunteers - a pilot study Indian. J Med Res, 2013; 137(5): 916-921.

16.Sharma V, Trakroo M, Subramaniam V, Sahai A, Bhavanani A, Rajajeyakumar M. Effect of fast and slow pranayama on perceived stress and cardiovascular parameters in young health-care students. Int $J$ Yoga, 2013;6:104. https://doi.org/10.4103/0973-6131.113400

17.Kjellgren A, Bood SA, Axelsson K, Norlander T, Saatcioglu F. Wellness through a comprehensive yogic breathing program - a controlled pilottrial.BMCComplementAlternMed,2007;7:43. https://doi.org/10.1186/1472-6882-7-43
18.Telles S, Vishwakarma B, Gupta RK, Balkrishna A. Changes in Shape and Size Discrimination and State Anxiety After Alternate-Nostril Yoga Breathing and BreathAwareness in One Session Each. Med Sci Monit Basic Res, 2019; 25: 121-127. https://doi.org/10.12659/MSMBR.914956

19.Zaccaro A, Piarulli A, Laurino M, Garbella E, Menicucci D, Neri B, Gemignani A. (2018). How Breath-Control Can Change Your Life: A Systematic Review on Psycho-Physiological Correlates of Slow Breathing. Front Hum Neurosci, 2018;12:353. https://doi.org/10.3389/fnhum.2018.00353

20.Pal GK, Velkumary S. Madanmohan. Effect of shortterm practice of breathing exercises on autonomic functions in normal human volunteers. Indian J Med Res, 2004;120(2):115-21.

21.Vk S, T D, M R, B G, Ab B. Impact of Fast and Slow Pranayam on Cardio Vascular Autonomic Function among Healthy Young Volunteers: Randomized Controlled Study. Altern Integr Med, 2018;07. https://doi.org/10.4172/2327-5162.1000265

22.Pramanik T, Sharma HO, Mishra S, Mishra A, Prajapati R, Singh S. Immediate effect of slow pace bhastrika pranayama on blood pressure and heart rate. $J$ Altern Complement Med, 2009;15(3):293-5. https://doi.org/10.1089/acm.2008.0440

23.Santaella DF, Devesa CRS, Rojo MR, Amato MBP, Drager LF, Casali KR, et al. Yoga respiratory training improves respiratory function and cardiac sympathovagal balance in elderly subjects: a randomised controlled trial. BMJ Open, 2011;1:e000085-e000085. https://doi.org/10.1136/bmjopen-2011-000085

24.Tyagi A, Cohen M. Yoga and heart rate variability: A comprehensive review of the literature. Int $J$ Yoga, 2016; 9(2): 97-113. https://doi.org/10.4103/0973-6131.183712

25.Chetan DK, Pawan SL, Pravin RK, Deepak MV, Suchita GS. Effect of Bhastrika Pranayama on "Shwasan Karma". Int. J. Res. Ayurveda Pharm, 2021;12(1):59. https://doi.org/10.7897/2277-4343.120114

26.Lau C, Yu R, Woo J. Effects of a 12-Week Hatha Yoga Intervention on Cardiorespiratory Endurance, Muscular Strength and Endurance, and Flexibility in Hong Kong Chinese Adults: A Controlled Clinical Trial. Evidence-Based Complementary and Alternative Medicine, 2015;2015:1-12. https://doi.org/10.1155/2015/958727

27.Baghel P, Shamkuwar S. Physiological Review of Qualitative Impact of Pranayama on Respiration. International Journal of Innovation and Research in Educational Sciences, 2017;4(1): 105-107.

28. Anand A, Patwardhan K, Singh R, Awasthi H. Effects of Pranayama on mental health and physical fitness in healthy University students. Yoga Mimamsa, 2018;50:27. https://doi.org/10.4103/ym.ym_15_17

29. Thangavel D, Gaur GS, Sharma VK, Bhavanani AB, Rajajeya kumar M, Syam SA. Effect of Slow and Fast Pranayama Training on Handgrip Strength and Endurance in Healthy Volunteers. Journal of Clinical and Diagnostic Research, 2014, 8(5): BC01-BC03. https://doi.org/10.7860/JCDR/2014/7452.4390

30.Gaurav V. (2011). Effects of Hatha Yoga Training on the Health-Related Physical Fitness. International Journal of Sports Science and Engineering, 2011;05(03):169-173. 


\section{Information about the authors:}

Baljinder Singh Bal; (Corresponding Author); https://orcid.org/0000-0003-2173-2748; bal_baljindersingh@yahoo.co.in; Department of Physical Education (T), Guru Nanak Dev University ; Amritsar, Punjab, India.

Parmjit Kaur; https://orcid.org/0000-0002-3370-7366; parmpurewal90@gmail.com; Department of Physical Education, PCM S.D. College for Women; Jalandhar, Punjab, India.

Davinder Singh; https://orcid.org/0000-0003-0833-6492; ds_rajput87@yahoo.in; Department of Physical Education, Kanya Maha Vidyalaya (Autonomous); Jalandhar Punjab, India.

Manoj Bhardwaj; https://orcid.org/0000-0003-0430-7408; manojthemaximus@yahoo.com; Department of Physical Education (T), Guru Nanak Dev University; Amritsar, Punjab, India.

\section{Cite this article as:}

Bal BS, Kaur P, Singh D, Bhardwaj M. Effects of 6-weeks Bhastrika Pranayama Intervention on health-related components of physical fitness. Physical Education of Students, 2021;25(4):230-238.

https://doi.org/10.15561/20755279.2021.0404

This is an Open Access article distributed under the terms of the Creative Commons Attribution License, which permits unrestricted use, distribution, and reproduction in any medium, provided the original work is properly cited http://creativecommons.org/licenses/by/4.0/deed.en

Received: 10.07 .2021

Accepted: 11.08.2021; Published: 30.08.2021 